\title{
Tachycardia of unknown Origin
}

\section{This is the first published case of onset of tachycardia despite triple rate-controlling medication during a rugby league match. The case highlights the importance of a thorough history to exclude Origin-induced tachycardia.}

\section{Michael H Toon BPharm, MB BS(Hons) Medical Registrar \\ Martin R Brown MB BS, MRCP, FRACP Cardiologist \\ 1 Mater Health Services, Brisbane, QLD. \\ 2 Advanced Heart Failure and Transplant Unit, Prince Charles Hospital, Brisbane, QLD. \\ michael.toon@ uqconnect.edu.au}

doi: 10.5694/mjal3.1064

\section{Clinical record}

A 40-year-old Queensland man on continuous telemetry for decompensated idiopathic dilated cardiomyopathy following explantation of an infected implantable cardiodefibrillator was noted to have abnormal tracing (Box) between 19:00 and 22:00 on 4 July 2012. The patient was well, symptom-free and in excellent spirits. His medication included digoxin $250 \mu \mathrm{g}$ daily, amiodarone $200 \mathrm{mg}$ daily and bisoprolol $7.5 \mathrm{mg}$ daily, with a resting heart rate of 60 beats per minute.

Telemetry showed asymptomatic variable persistent sinus tachycardia over a 3 -hour period on the previous evening.

Further history revealed that the patient had been watching the deciding match of the annual State of Origin rugby league series between Queensland and New South Wales

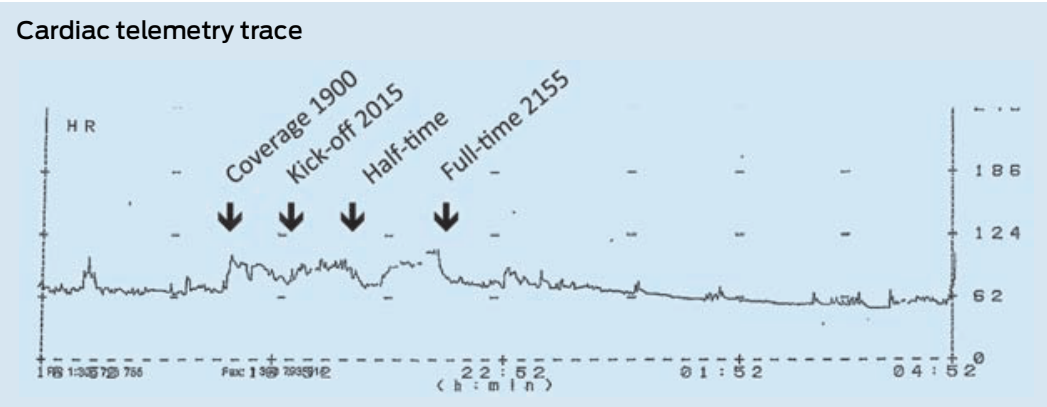

on television. The Box shows the onset of the tachycardia at the start of the match coverage at 19:00, with a second peak at kick-off (20:15). The recorded rhythm was sinus with left bundle branch block (QRS duration, $140 \mathrm{~ms}$ ). The sinus tachycardia persisted throughout the first half until the halftime interlude, when normocardia resumed. The tachycardia reoccurred at the start of the second half, reaching a peak in the dying minutes of the game, when the patient's home state, Queensland, scored a field goal at 75 minutes - followed by a missed long-range field goal by the NSW halfback in the final minute of the game - securing victory by one point for Queensland (21:55).

\section{Discussion}

This case illustrates a sustained run of tachycardia in a continuously monitored inpatient with cardiomyopathy, which terminated itself after trying circumstances and which occurred despite multiple rate-limiting medications.

Had the patient's defibrillator still been in place, it mercifully would not have been activated, as his defibrillation threshold was set at 180 beats per minute. Origininduced tachycardia should be a differential diagnosis for asymptomatic sinus tachycardia in passionate Queensland rugby league supporters, whose only cure when watching televised coverage is to turn off their televisions.

Competing interests: No relevant disclosures.

Received 13 May 2013, accepted 80ct 2013.

$\square$ 